\title{
GCU
}

Glasgow Caledonian

University

University for the Common Good

\section{Are Latinos who commit sexual offenses different? A closer examination of characteristics and offense patterns}

Fraga Dominguez, Silvia; Jeglic, Elizabeth L.; Calkins, Cynthia; Leguizamo, Alejandro

Published in:

Sexual Abuse

DOI:

$10.1177 / 1079063217710480$

Publication date:

2018

Document Version

Author accepted manuscript

Link to publication in ResearchOnline

Citation for published version (Harvard):

Fraga Dominguez, S, Jeglic, EL, Calkins, C \& Leguizamo, A 2018, 'Are Latinos who commit sexual offenses different? A closer examination of characteristics and offense patterns', Sexual Abuse, vol. 30, no. 7, pp. 846-868 . https://doi.org/10.1177/1079063217710480

\section{General rights}

Copyright and moral rights for the publications made accessible in the public portal are retained by the authors and/or other copyright owners and it is a condition of accessing publications that users recognise and abide by the legal requirements associated with these rights.

Take down policy

If you believe that this document breaches copyright please view our takedown policy at https://edshare.gcu.ac.uk/id/eprint/5179 for details of how to contact us. 
Are Latinos Who Commit Sexual Offenses Different? A Closer Examination of Characteristics and Offense Patterns 


\begin{abstract}
Research examining ethnic and cultural differences among individuals who commit sex offenses remains limited. Specifically, literature focusing on sex offenses committed by Latinos is scarce. Using archival data from a large sample of individuals who committed sex offenses, this study explored differences between Latino, White, and African-American individuals related to their characteristics, the offenses, and the victims. Latinos in the sample were more likely to have a lower educational level, and to be living with the victim, than either their White or AfricanAmerican counterparts. To further understand the influence of cultural background, the study also examined differences within the Latino group based upon their country of origin. Within the Latino sample, differences emerged in their educational level, criminal background, and psychiatric history. These findings are discussed as they pertain to future research and current practices related to the management and treatment of Latinos who commit sexual offenses.
\end{abstract}

Key words: sex offending, Latino, ethnicity, treatment 


\section{Are Latinos Who Commit Sexual Offenses Different? A Closer Examination of Characteristics and Offense Patterns}

The Latino population has been identified as the fastest growing and most influential minority ethnic group in the U.S., and it is estimated that by the year 2050, 1 in 3 individuals living in the U.S. will be of Latino descent (Kilgust, 2009; Stowell, Martinez, \& Cancino, 2012; Varghese, Hardin, \& Bauer, 2009). ${ }^{1}$ However, Latinos’ involvement in the criminal justice system has risen more rapidly than their population growth, including those convicted of sex crimes (Smith-Socaris, Perry, \& Fox-Mullen, 2006), suggesting an over-representation of this group within the system (Lopez \& Livingston, 2009). While a great deal of research has focused on understanding the causes and correlates of sexual offending (e.g., Barbaree, Seto, Langton, \& Peacock, 2001; Gannon \& Polaschek, 2006; Seto \& Lalumiere, 2010; Ward \& Beech, 2006), research efforts have mostly focused on sexual offending committed by White males. Research conducted with minorities and sexual offending behavior tends to be lacking, with very few studies either including or specifically identifying Latinos ${ }^{2}$ within their samples. Consequently, relatively little is known about this group and its involvement in sexually-based crimes.

Those incarcerated in the U.S. criminal justice system are racially and ethnically diverse. However, the majority of research investigating differences between racial and ethnic groups has concentrated on criminal justice outcomes, studying issues such as sentencing disparities without addressing how race/ethnicity may have an impact on offending (e.g., Caravelis, Chiricos, \&

\footnotetext{
${ }^{1}$ Currently there are approximately 55.3 million Latinos living in the U.S., of which 35\% are foreign-born (Stepler \& Brown, 2016).

${ }^{2}$ Throughout this article, the terms of "African-American" and "White" will be used. "Latino" will be used over "Hispanic"; however, we acknowledge that some of the authors cited may have used other terms. Whenever we refer to "Latinos," we will be referring to any person that identifies as Latino, regardless of their race. Because of the fact that we will be comparing racial and ethnic groups, both terms will be used throughout this manuscript.
} 
Bales, 2011). Overall, research has found that Latino and African-American defendants tend to be sentenced more harshly than White defendants (Bales \& Piquero, 2012; Spohn \& Holleran, 2000; Steffensmeier \& Demuth, 2000; Ulmer \& Johnson, 2004).

\section{Multiracial and Multicultural Research on Sexual Offending}

The limited research examining race and ethnicity in relation to sex offending has mainly focused on the distinction between African-Americans and Whites who commit sexual offenses. For example, reviews of archival data show that African-Americans who commit sexual offenses tend to use more physical force in their offenses than Whites, especially if the victim is a stranger (Heilbrun \& Cross, 1979; Leguizamo, Peltzman, Carrasco, Nosal, \& Woods, 2010). On the other hand, as compared to African-Americans, Whites who commit sexual offenses tend to be more likely to present a pattern of sexual deviancy, use pornography in their offenses, be closely related to their victims, and engage in non-contact sexual offenses (Heilbrun \& Cross, 1979; Leguizamo et al., 2010; Murphy, DiLillo, Haynes, \& Steere, 2001).

Certain facts have also emerged in similar studies regarding Latinos who commit sexual offenses. For example, Mexican-Americans who committed sexual offenses were more likely to offend against stepdaughters (Carrasco \& Garza-Louis, 1997; Huston, Parra, Prihoda, \& Foulds, 1995), and Latinos were significantly less educated and more likely to have been raised in low socioeconomic status (SES) households than were African-Americans or Whites (Leguizamo et al., 2010). In spite of these research efforts, comparative research on sex offending involving Latinos is still relatively sparse. Steffensmeier and Demuth (2001) have attributed this deficit to the general tendency to merge Latinos in with Whites when describing participants’ race, 
disregarding their ethnic identity. In addition, Kilgust (2009) highlighted that there is an overall lack of definitional clarity in participant racial-ethnic group membership in the existing research.

Both of these issues can result in a lack of understanding about the specific characteristics of Latinos who commit sex offenses, which in turn may impact practice. For example, data used in the development of tools to predict recidivism lack the racial and ethnic diversity that characterizes the U.S. population (Varela, Boccaccini, Murrie, Caperton, \& Gonzalez, 2013), which may explain the decreased ability of the Static-99 (Hanson \& Thornton, 2000) to predict sexual recidivism for Latinos compared to Whites who have committed sexual offenses. This is consistent with European research suggesting that the predictive validity of some risk assessment tools may not generalize across offender ethnic group or immigration status (Långström, 2004). More recently, Leguizamo, Lee, Jeglic, and Calkins (2015) found that the Static-99 was able to predict recidivism among Latinos of continental U.S. or Puerto Rican origin but that the measure performed poorly with Latinos who were not born in those countries. Further, it has been noted that the knowledge of the characteristics associated with recidivism underlying risk assessments is based upon those who are prosecuted, not being representative of all individuals who commit sexual offenses — and this may vary by racial and ethnic group (Larcombe, 2012).

This lack of cultural understanding is also likely to have an impact upon treatment. According to the responsivity principle of the Risk-Need-Responsivity (RNR) model of offender treatment, effective treatment interventions need to take into account an individual's background, knowledge and learning style (Andrews \& Bonta, 1998). A critical part of an individual’s background is his belonging and identification with an ethnic group; consequently, cultural characteristics need to be assessed and addressed as part of treatment. For example, minority 
individuals who have committed a sexual offense may perceive certain aspects of treatment programs to be culturally insensitive (Cullen \& Travin, 1990; Patel \& Lord, 2001). In addition, Spanish-speaking individuals in particular may experience both language barriers and transcultural factors that have an effect on the evaluation and engagement processes.

Despite the general lack of comparative research, there have been some efforts to identify cultural factors that may contribute to sexual offending behaviors among Latinos. Of the existing literature that has included Latino samples, a sizeable portion has focused on the influence of masculine identities (e.g., Carrasco \& Garza-Louis, 1997; Cullen \& Travin, 1990; Moro, 1998; Santana, Raj, Decker, La Marche, \& Silverman, 2006). For example, Carrasco and Garza-Louis reported that Latinos who committed sex offenses showed greater adherence to traditional values, as well as more rigid attitudes towards traditional gender roles as compared to other racial and ethnic groups. They also found that Latinos who committed sexual offenses seemed to display higher levels of cognitive distortions related to masculine identity, regarding themselves as macho (i.e., a strong, noble, brave person) when in reality they were demonstrating machismo (i.e., an exaggerated sense of masculinity associated with domineering behavior, bravado, and aggression). However, it is important to note that the majority of work discussing the role of machismo and sexual offending has not been empirical in nature and has too narrowly focused on this single factor. Finally, other researchers have found that Latinos who commit sex offenses have disproportionate involvement in statutory rape, which usually refers to acts of rape committed against a minor under the age of consent (Flores de Apodaca, Schultz, Anderson, \& McLennan, 2005; Kilgust, 2009). 
While comparative research is vital to understanding responsivity issues broadly related to membership in a racial or ethnic group, it is necessary to bear in mind the heterogeneity that characterizes the Latino population. Although usually categorized as a homogenous ethnic group by researchers, Latinos from different parts of the world differ in terms of socioeconomic, cultural, and genetic perspectives, and they also encompass various racial origins (Burchard et al., 2005); yet there is a dearth of research examining within-group differences among Latinos.

\section{The Present Study}

The current study will add to the nascent body of research on sexual offenses committed by Latinos by examining offender, index offense, and victim characteristics, together with risk assessment scores among a large sample of African-Americans, Whites, and Latinos convicted of a sexual offense. Previous research examining Latinos who have been convicted of sexual offenses has been somewhat limited in scope, e.g., examining only the influence of masculine identity. Given the large number of Latinos in our sample, this study aims to more broadly examine ways in which Latinos may differ from both African-Americans and Whites convicted of a sex offense. Further, we will explore factors related to country of origin, thus being the first study to examine differences in sex offense patterns within a sample of Latinos.

On the basis of previous research findings, it is hypothesized that Latinos who commit sexual offenses (as compared to Whites and African-Americans who commit sexual offenses) will have lower education levels and lower SES. It is also anticipated that, as compared to Whites, Latinos in the sample will have more female and related victims, will be more likely engage in contact sex offenses, and will be less likely to have pornography involved in their offenses. Latinos are also expected to be less likely to use physical force in their offenses as 
compared to African-American offenders. As some of the variables included in our analyses have not been previously studied in the literature we will also conduct exploratory analyses between groups related to other demographic characteristics, type of index offenses and behaviors, the relationship with the victim, and variables related to prior criminal history. Similarly, given the lack of research examining differences within subsamples of Latinos who commit sexual offenses, our analyses of differences within the Latino group will be exploratory.

\section{Method}

\section{Participants and Design}

The data used in this study were gathered from the archival records of a larger study examining sex offender placement within the criminal justice system (Mercado, Jeglic, \& Markus, 2011). They were obtained from the archival files of males who had been convicted of a sexual offense, incarcerated and then later released from New Jersey state prisons. The data comprised a random sample of approximately $45 \%$ offenders who committed sexual offenses from the general prison population and $100 \%$ of those who were incarcerated in a specialized treatment facility designed to treat those who commit sexual offenses over an 11 year period. ${ }^{3}$ Trained research assistants coded file data using a data collection tool developed to gather relevant demographic information, criminal history, index offense characteristics, and victim information (see Mercado et al., 2011).

The initial sample was composed of 3,194 males convicted of an index sex offense. The race and ethnicity of the participants was established by the status in the files and transcribed accordingly by the research assistants. A small number $(n=93)$ of offenders who belonged to

${ }^{3}$ Groups did not differ overall depending on the placement (see Mercado, Jeglic, \& Markus, 2011, for more detailed information). 
racial and ethnic groups other than White, African-American, and Latino were excluded from the analyses, resulting in a final sample of 3,101 male offenders $(M=44.9, S D=12.3)$ and divided in three groups: White $(N=1,310,42 \%)$; African-American $(N=1,158,37 \%)$; and Latino $(N=$ 633, 21\%). These classifications were based upon Department of Correction's designations. Within the Latino sample, 485 (77\%) were Spanish-speaking, and for 388 (61\%) Spanish was their first language.

The Latino sample ( $n=633$ ) was then further grouped by country of origin. Cases whose country of origin was unknown were deleted, resulting in a final sample of 621 Latinos convicted of a sexual offense. The rationale behind the division was geographic location, assuming more similarities between countries located in the same geographic area as well as a similar immigration history. We recognize that country of origin and the country where the individual was raised may differ; however, the latter information was not available. Factors relating to immigration status were also taken into account, predicting potential differences for participants born in the continental U.S., or U.S. territories (Puerto Rico), as compared to those migrating from other South and Central American countries and the other Caribbean Islands. Puerto Rico was considered a separate geographical area since it is a U.S. territory, which may differentiate it from other Caribbean islands - i.e., more assimilated to U.S. culture and with a different immigration history. The sample was therefore divided in the following groups: those born in the continental U.S. ( $n=217,35 \% ; m=40.9$, $s d=10.5)$; those born in Puerto Rico $(n=142,23 \%$; $m=47.5, s d=11.4$ ); those born in Central America, the Caribbean Islands (other than Puerto Rico), and Mexico ( $n=182,29 \% ; m=39.7, s d=13.4)$; and those born in South America $(n=$ 80, $13 \% ; m=43.1, s d=13.1$ ). We will be referring to the group comprising Central America, 
the Caribbean, and Mexico as “Central America” throughout the manuscript. Information about the three groups' age and countries of origin is included in Table 1.

\section{Materials}

Data collection tool. The data used in this study were gathered and coded by trained MA-level research assistants from the offender files. These data included demographic characteristics, criminal history, index offense, and victim characteristics, and a measurement of risk of recidivism (Static-99 scores ${ }^{4}$ ). Some of the variables were coded as present or absent (e.g., prior employment), while others had different categories (e.g., type of index offense).

Demographics. Presence of reported childhood abuse/neglect, existence of any psychiatric history, low educational level ( $8^{\text {th }}$ grade or lower), SES (coded in the files as low, middle, or high), prior employment (employment prior to incarceration).

Index Offense Variables. a) Type of index offense: adult sexual assault, molestation of a minor child, voyeurism or exhibitionism, computer sex-related crime; b) Index offense behaviors: physical contact involved, pornography involved in all or part of the offense, alcohol or drugs involved, alcohol or drugs supplied to the victim, offender intoxicated at the moment of the offense, offender physically violent (if the index crime involved slapping, punching, or hitting), use of a weapon during the crime, use of threats to the victim.

Victim Characteristics. Victim's gender (male, female, male and female), age (younger than 13, 13-17, older than 17), offender living with the victim, type of relationship (immediate family, extended family, stepfamily, acquaintance, and stranger).

\footnotetext{
${ }^{4}$ This measurement of recidivism was included on the basis of its frequent use in the Criminal Justice System and recent findings of its general applicability with some Latino populations (Leguizamo et al., 2015)
} 
Prior Criminal History. Charged/convicted of a sexual crime, charged/convicted of a non-sexual crime, charged/convicted as a juvenile, charged/convicted for a sexual crime as a juvenile, age at the first sexual crime, age at the first non-sexual crime.

Static-99. ${ }^{\mathbf{T}}$ The Static-99 (Hanson \& Thornton, 2000) is an empirically-derived measure of actuarial risk developed to predict sexual recidivism in adult males who commit sexual offenses that includes 10 items related to criminal history, victim characteristics, and demographics (Hanson, Sheahan, \& VanZuylen, 2013). It has total scores ranging from 0 to 12 , which can be translated into risk levels that range from 0 (lowest risk) to 6+ (highest risk). The reported predictive accuracy for sexual recidivism is moderate $(r=.33$, ROC -Receiver Operating Characteristic- area $=.71$ ) and is also moderate for violent (including sexual) recidivism $(r=.32$, ROC area = .69) (Hanson \& Thornton, 2000). The Static-99 data were scored by clinicians (as contained in the participants' record) and/or by trained graduate research assistants when Static-99 data were not available in the file. The level of agreement in Static-99 scores based on raters was measured using the Intraclass Correlation Coefficient (ICC) and was calculated for this sample in Quesada, Calkins, and Jeglic (2014). The ICC obtained was .89, suggesting excellent agreement (Cicchetti, 1994).

\section{Procedure}

Data analyses. Descriptive analyses were conducted to assess the characteristics of the Latino group compared to the White and African-American groups. Chi-square tests were used for categorical variables and ANOVAs for continuous variables. In the cases of continuous variables where the assumption of the homogeneity of variances was violated, as assessed by

\footnotetext{
${ }^{5}$ The Static-99 has been used instead of its revised version Static-99R because this was the scale coded in files.
} 
Levene's test for equality of variances, Welch’s ANOVAs were conducted. Post-hoc analyses (standardized z, Games Howell, Tukey post-hoc tests) were also conducted when the results were significant in order to be able to interpret the differences between the specific groups along with odds ratios. The same series of descriptive analyses, comparisons and post-hoc analyses were conducted looking at the different groups within the Latino subsample. In order to calculate effect sizes, the omega-squared coefficient was used.

\section{Results}

\section{General Sample}

There were several significant differences between groups in demographic variables. ${ }^{6}$ Significant differences between groups were found in educational level attained, $\chi^{2}(4, N=3054)$ $=172.32, p<.001$, such that Latinos in the sample were more likely to have low educational levels relative to Whites and African-Americans. Specifically, Latinos were 3.3 times more likely than Whites and 4.3 times more likely than African-Americans in the sample to have a low educational level. There were also significant differences by race/ethnicity on Socioeconomic Status (SES) level, $\chi^{2}(4, N=1252)=52.25, p<.001$; African-Americans and Latinos in the sample were 2.6 times and 1.9 times more likely to have low SES level, respectively, when compared to Whites. In terms of other comparisons, there were significant differences between ethnic/racial groups on the reported experience of childhood abuse/neglect, $\chi^{2}(2, N=2873)=$ 30.57, $p<.001$, with Whites who had committed a sexual offense being more likely to have reported childhood abuse or neglect compared to African-Americans and Latinos. Similarly, the psychiatric history varied between ethnic/racial groups, $\chi^{2}(2, N=3005)=71.89, p<.001$, with

\footnotetext{
${ }^{6}$ Due to the amount of variables and analyses, only significant differences will be reported in the results section. We will comment on any significant difference, even if they do not include our focus group.
} 
Whites being more likely to have a history of psychiatric problems compared to both AfricanAmericans and Latinos. Finally, the groups differed on their prior employment status, $\chi^{2}(2, N=$ 2999) $=62.25, p<.001$, with African-Americans being less likely to have been employed prior to the offense in relation to Whites and Latinos. Comparisons of demographic variables between groups are presented in Table 2.

The groups differed significantly on index offense variables. The type of index offense varied significantly by race/ethnicity, $\chi^{2}(14, N=3071)=145.39, p<.001$, with analyses indicating that African-Americans were more likely to have adult sexual assault as their index offense as compared to both Whites and Latinos. On the other hand, molestation of a minor child was more common for Latinos and Whites as compared to African-Americans. Finally, Whites were more likely to engage in non-contact offenses, such as voyeurism/exhibitionism and computer sex-related crimes as compared to the other two groups.

With respect to index offense behaviors, we found significant differences between groups in the use of physical contact, $\chi^{2}(2, N=3073)=34.72, p<.001$, revealing that Whites' offenses were less likely to involve physical contact as compared to both African-Americans’ and Latinos’. The involvement of pornography also varied significantly among racial/ethnic groups, $\chi^{2}(2, N=2462)=77.48, p<.001$. Specifically, offenses committed by Whites were more likely to involve pornography compared to those committed by African-Americans and Latinos.

Differences were found in the use of physical violence, $\chi^{2}(4, N=2039)=53.90, p<.001$, revealing that African-Americans in the sample were more likely to be physically violent during the offense compared to both Whites and Latinos. In addition, differences were found in the use of a weapon, $\chi^{2}(2, N=3033)=66.89, p<.001$, with African-Americans being more likely to 
use a weapon during the offense compared to Whites, and Latinos. The use of threats was also significantly different between the groups, $\chi^{2}(2, N=2049)=13.43, p=.001$, revealing a higher likelihood of threatening behavior among African-Americans compared to Whites. Other significant differences were found between groups in the supplying of alcohol/drugs to the victim, $\chi^{2}(2, N=1125)=11.81, p=.003$; Whites were more likely to display this behavior in comparison to African-Americans and Latinos. The frequencies and percentages on offenserelated variables by racial/ethnic group are presented in Table 3.

With respect to victim variables, significant differences were found by race/ethnicity regarding the gender of the victim, $\chi^{2}(4, N=3024)=124.73, p<.001$. Whites were more likely to have male victims compared to African-Americans and Latinos. Specifically, Whites were 2.7 times more likely to have male victims than were African-Americans and 3.2 times more likely than Latinos. Whites were less likely to have female victims compared to both AfricanAmericans and Latinos. They were also more likely to have both male and female victims compared to African-Americans. Finally, there were significant differences by race/ethnicity regarding whether the offender was living with the victim at the time of the offense, $\chi^{2}(2, N=$ 1993) $=30.39, \mathrm{p}<.001$, with Latinos in the sample being more likely than African-Americans to be living with the victim. Significant differences were also found regarding the specific relationship with the victim, $\chi^{2}(16, N=3024)=71.71, p<.001$. Whites were more likely to have a victim within the immediate family, and Latinos and Whites were more likely to have a victim within the stepfamily, in comparison to African-Americans. Meanwhile, AfricanAmericans were more likely to have a victim that was an acquaintance compared to Whites, and more likely to have a stranger as a victim compared to Latinos. Finally, significant differences by race/ethnicity were also found regarding the age of the first sexual offense victim, $\chi^{2}(4, N=$ 
2081) $=67.58, p<.001$, revealing that Whites and Latinos were more likely to have victims younger than 13 compared to African-Americans. African-Americans were more likely to have victims aged 13 to 17 compared to Latinos, and were also more likely to have victims older than 17 compared to both Latinos and Whites. Differences between groups on victim characteristics are presented in Table 4.

Several differences were found with respect to participants’ prior criminal histories. Significant differences were found by race/ethnicity in the charges/conviction of sexual crimes, $\chi^{2}(2, N=2940)=43.79, p<.001$, with African-Americans being more likely to have been previously charged/convicted of sexual crimes compared to Latinos. Significant differences were also found regarding the charges/conviction of non-sexual crimes, $\chi^{2}(2, N=3055)=185.53, p<$ .001 , with African-Americans being more likely to have been charged/convicted of non-sexual crimes compared to Whites and Latinos. Significant differences were also found for charges/convictions as juveniles, $\chi^{2}(2, N=2555)=99.54, p<.001$, with African-Americans being more likely to have been charged/convicted as juveniles compared to both Whites and Latinos. Finally, there were significant differences by race/ethnicity in the charge/conviction of a sexual crime as a juvenile, $\chi^{2}(2, N=1602)=18.51, p<.001$, with African-Americans being more likely to have been charged/convicted of a sex crime as juveniles compared to Latinos. Results for these variables are presented in Table 5.

Continuous variables related to criminal history were also analyzed. One-way Welch’s ANOVAs were conducted to compare differences between racial/ethnic groups on continuous variables since variances among groups were not equal. When differences were found, GamesHowell post-hoc analyses were conducted. The age at the first sexual offense varied among 
different races/ethnicities, $F(2,1418.186)=29.79, p<.001$. African-Americans who committed sexual offenses were significantly younger $(M=27.21, S D=10.04)$ than Whites $(M=30.72, S D$ $=12.31 ; p<.001)$, and Latinos $(M=30.23, S D=10.81 ; p<.001)$ in our sample. This effect size was in the small range $\left(\omega^{2}=.022\right)$. The age of the first non-sexual offense differed between racial/ethnic groups, $F(2,855.766)=34.33, p<.001$, with a small effect size $\left(\omega^{2}=.032\right)$. GamesHowell post-hoc analyses revealed that African-Americans in the sample were significantly younger $(M=19.91, S D=6.093)$ than Whites $(M=22.37, S D=11.061 ; p<.001)$, and also than Latinos $(M=23.35, S D=8.097 ; p<.001)$.

Finally, Static-99 scores were also analyzed by conducting a one-way Welch’s ANOVA and significant differences were found by race/ethnicity, $F(2,1327.533)=57.31, p<.001$, with a small effect size $\left(\omega^{2}=.047\right)$. The risk score for African-Americans was significantly higher $(M=$ 3.15, $S D=1.92)$ than that of Whites $(M=2.79, S D=2.11 ; p<.001)$ and of Latinos $(M=2.09$, $S D=1.64 ; p<.001)$. Whites also had a significantly higher risk score as compared to Latinos in the sample $(p<.001)$.

\section{Latino Sample}

In order to further explore specific differences among Latino sub-groups, the Latino group was subdivided into four categories by geographic origin of birth. Results are presented in Tables 6 through 9. Only significant differences are reported in text.

There were significant differences between racial/ethnic groups on reported experience of childhood abuse/neglect $\chi^{2}(3, N=581)=29.02, p<.001$, showing that U.S.-born Latinos and those born in Puerto Rico were more likely to have reported childhood abuse or neglect, compared to Latinos of Central American or South American origin. Similarly, the psychiatric 
history varied depending on participants' countries of origin, $\chi^{2}(3, N=605)=36.53, p<.001$, with U.S.-born Latinos and Latinos born in Puerto Rico being more likely to have a history of psychiatric problems compared to both those born in Central America and South America. There were significant differences between the groups in educational level, $\chi^{2}(6, N=621)=38.32, p<$ .001, showing that Latinos of Central American origin were more likely to have low educational level ( (th $^{\text {grade }}$ or less) relative to U.S.-born Latinos. The groups also differed on their prior employment status, $\chi^{2}(3, N=605)=35.30, p<.001$, revealing that Latinos born in Puerto Rico were less likely to have been employed prior to the offense in relation to those of Central American and South American origin. Finally, there were significant differences by country of origin on the SES level, $\chi^{2}(9, N=606)=20.27, p=.016$ with Latinos of South American origin being more likely to be of middle SES level compared to those born in Puerto Rico. The number of participants with low and high SES level did not differ significantly across groups.

Significant differences were found between groups of countries of origin in the charges/conviction of a sexual crime, $\chi^{2}(3, N=592)=35.89, p<.001$, with U.S.-born Latinos being more likely to have been charged or convicted of sexual crimes as compared to those born in Central America and South America. Significant differences were also found regarding the charges/conviction as juveniles, $\chi^{2}(3, N=487)=50.67, p<.001$, with U.S.-born Latinos being more likely to have been charged or convicted as juveniles relative to those born in Central America and South America.

A one-way ANOVA analysis indicated that the average age at the first sexual offense was different between countries of origin, $F(3,522)=12.82 ; p<.001$, indicating that U.S.-born Latinos were younger $(M=26.83, S D=9.79)$ than those born in Puerto Rico $(M=33.59, S D=$ 
10.80) and this difference was statistically significant $(p<.001)$. U.S.-born Latinos were also significantly younger $(M=26.83, S D=9.79)$ than those born in Central America $(M=29.86, S D$ $=10.33, p=.044)$ and in South America $(M=33.44, S D=11.74, p<.001)$. This result had a medium effect size $\left(\omega^{2}=.063\right)$. Further, those born in Central America $(M=29.86, S D=10.33)$ were significantly younger than those born in Puerto Rico $(M=33.59, S D=10.80, p=.017)$. Welch's ANOVA indicated that the age of the first non-sexual offense differed between countries of origin, $F(3,107.561)=10.64 ; p<.001$, with a medium effect size $\left(\omega^{2}=.077\right)$. Games-Howell post-hoc analyses revealed that U.S.-born Latinos were significantly younger ( $M$ $=20.92, S D=6.690)$ than those of Central American origin $(M=25.86, S D=8.71, p<.001)$ and of South American origin $(M=27.43, S D=8.22, p=.001)$, but no other group differences were statistically significant.

Finally, Static-99 scores were also analyzed by conducting a one-way Welch’s ANOVA and significant differences were found by groups of countries of origin, $F(3,194.031)=11.46, p$ $<.001$ with a medium effect size $\left(\omega^{2}=.063\right)$. The risk score for U.S.-born Latinos was significantly higher $(M=2.64, S D=1.85)$ than that of those born in Central America $(M=1.65$, $S D=1.23, p<.001)$ and that of those born in South America $(M=1.60, S D=1.57, p<.001)$ but no other group differences were statistically significant.

\section{Discussion}

Through this study we sought to provide a more nuanced understanding of Latinos who commit sexual offenses by comparing them to their White and African-American counterparts with respect to demographics, victim characteristics, offense characteristics, and criminal history. Further, given the heterogeneity of Latinos as a population, we subdivided the Latino sample by 
country of origin and explored within-group differences. Overall in this study we found that Latinos who committed sexual offenses differed from African-American and White offenders in our sample with regard to the relationship with the victim, educational level, employment status, and level of risk. Within the Latino sample, those from distinct groups of countries of origin differed in terms of their educational level, SES, criminal history, and psychiatric history.

As hypothesized, some of our findings regarding Latinos who commit sexual offenses were in line with previous research. For example, similar to the results of Carrasco and GarzaLouis (1997), Latinos were more likely to offend against stepfamily members. In addition, almost half of the Latinos in our sample who were living with somebody at the time of the offense were living with the victim, suggesting that these were family members to whom the offender had easy access and who would be more easily controlled by the offender given their authority and power over the victim. These findings are of particular importance given that family offenses are generally the least reported (Priebe \& Svedin, 2008). Specifically, if the offender is supporting the family financially, reporting the abuse would cause significant hardship. In addition, this could complicate reintegration following the completion of the sentence as the offender would likely be prohibited from contact with the victim, which would separate him from family and potential social support, which in turn could increase the risk of destabilization (Burchfield \& Mingus, 2008; Hanson \& Harris, 1998, 2001).

Contrary to our hypotheses, Latinos who committed sexual offenses were not significantly more likely to have a lower SES level than their African-American or White counterparts. However, we did find that they were more likely to have a lower education level than either African-Americans or Whites. This may impact the delivery of treatment since, 
according to the responsivity principle of the RNR model, treatment needs to be tailored to address learning style and background knowledge (Andrews \& Bonta, 1998). Therefore, treatment programs may need to be modified to address literacy and education issues in certain groups of offenders, as well as potential linguistic issues. Spanish-speaking participants, depending on their level of education in their countries of origin (if immigrants) may vary dramatically with respect to their command of the language, even if they are native speakers. Moreover, utilization of the RNR model may necessitate some level of modification given barriers that Latinos encounter in treatment (e.g., Kouyoumdjian, Zamboanga, \& Hansen, 2003), such as ethnic mismatch with the therapist, lack of understanding of the clients' culture, and discrimination. As a result, Latinos may require more time, and a more careful approach by treatment providers, in order for a therapeutic relationship to be established.

We also found that Latinos who commit sexual offenses were more likely to have a history of pre-incarceration employment. Even though the barriers to employment are common for those with a history of sexual offenses (Levenson, Brannon, Fortney, \& Baker, 2007), this finding suggests that they would be more likely than those who were unemployed prior to incarceration to obtain post-incarceration employment (Ramakers, Van Wilsem, NieuwBeerta, \& Dirkzwager, 2016; Visher, Debus, \& Yahner, 2008). Post-incarceration employment has consistently been identified as a factor that leads to desistance from offending behavior, since it involves a constructive and rewarding activity and can also ideally provide a sense of satisfaction and accomplishment (de Vries Robbe, Mann, Maruna, \& Thornton, 2015).

Latinos in our sample were also found to have lower documented risk as measured by the Static-99 than either African-Americans or Whites, consistent with previous research that found 
relatively low risk scores among Latinos (Varela et al., 2013). However, since many actuarial tools have not been normed using Latino samples, this does not necessarily imply that Latinos are in fact at lower risk of reoffending. Few researchers have assessed the predictive validity of risk assessment instruments with Latino samples (e.g., Hanson, Lunetta, Phenix, Neeley, \& Epperson, 2014; Leguizamo et al., 2015; Varela et al., 2013). Others have postulated that the lower risk scores observed among Latinos may be due in part to a lack of historical data related to poor records from the country of origin of those who have not been born in the U.S. (Leguizamo et al., 2015).

Additionally, we found several differences within the Latino group based upon country of origin. For example, Latinos born in the U.S. were significantly more likely to have a previous criminal history for both sexual offenses as adults and non-sexual offenses as juveniles, and to have an earlier onset of offending than Latinos born outside of the U.S. Nonetheless, as mentioned previously, the lack of historical criminal data provided for offenders who were not born in the U.S. could explain these findings (Leguizamo et al., 2015). A similar problem related to accessibility of information could be behind the higher incidence of psychiatric problems and reported rates of childhood abuse for those born in the U.S. and Puerto Rico. Overall there are data suggesting that at least U.S.-born Latinos report higher rates of psychiatric disorders compared to Latino immigrants. However, this could be due to issues related to rates of reporting, cultural understanding of mental illness, and accessibility of mental health services (Alegria et al., 2008; American Psychiatric Association, 2013; Bentall, 2003). Finally, it seemed that Latinos who commit sexual offenses differed in their educational level and SES when they were grouped by country of origin. The higher likelihood of Latinos of South American origin to have a middle SES level could relate to the suggestion that migration from South America to the 
U.S. is more selective in terms of class origin (Connor \& Massey, 2011). This could be explained by the higher financial costs of migration linked to less geographical proximity as compared to other countries wherefrom Latino immigrants originate, resulting in more South American immigrants coming from middle class families and, possibly, with higher educational achievement.

Finally, while not the primary focus of this paper, we found that our results were consistent with previous research examining differences between Whites and African-Americans who commit sexual offenses. For example, similar to the work of Kirk (1975), Leguizamo and colleagues (2010), and Murphy and colleagues (2001), we found that African-Americans who commit sexual offenses were more likely to use physical force, while their White counterparts had less physical contact with their victims, more victims within the immediate family, and more involvement of pornography in their offenses. Additionally, Whites in our sample were more likely to have male victims than African Americans, while African-Americans were more likely to use threats and a weapon in their index offense. Therefore, the available findings seem to indicate that African-Americans who commit sexual offenses may be more likely to be violent in their offenses, which could be because of a higher tendency to offend against adults (needing higher levels of force to subdue them), while Whites may be more likely to offend against children. In addition, African-Americans were more likely to have an extensive criminal history, both related to general offending and to sex offending, compared to the other groups. They were also comparatively more likely to have low SES level and to not be employed prior to incarceration. This is relevant because socioeconomic disadvantage has been found to be a predictor of levels of lethal violence (Stowell et al., 2012), potentially indicating more risk of general offending within this group. 


\section{Limitations}

This study is not without limitations, most of which are related to the use of archival data. Since the original information was not gathered for the purposes of this study, and was collected from prison files, we had a substantial amount of missing data. ${ }^{7}$ In addition, the data collection process was large in scope and lengthy, involving numerous research assistants, and the nature and scope of the project are bound to result in some inconsistency across coders-however, we did note excellent ICCs for the Static-99, which suggests that overall there was good inter-rater reliability across raters. Further, since we used a large proportion of the New Jersey population of offenders who committed a sexual offense, we assessed groups as they presented in the sample-thus, our sample sizes were unequal impacting comparisons across groups. We also only assessed those who were arrested and serving a sentence for sex crimes and this is not necessarily representative of all those who engage in sexual offending behavior. Therefore, there may be different disclosure rates between victims of differing racial/ethnic groups (see Kenny \& McEachern, 2000; London, Bruck, Ceci, \& Shuman, 2005, for more detailed information about differences in disclosure rates). In addition, race/ethnicity was determined by the Department of Corrections and thus individuals could self-identify differently or be miscategorized. Also, as this was a sample of incarcerated individuals the findings of this study may not generalize to all individuals of Latino descent who have committed sexual offenses. Another limitation is linked to the characteristics of the Latino population included in this sample. Since the participants in this sample were located in one Northeastern state, the characterization of the Latino sample

\footnotetext{
${ }^{7}$ While we ascertained that the missing data was randomly distributed, some variables had more missing data than others (see Mercado, Jeglic, \& Markus, 2011).
} 
cannot be generalized to the Latino population in the U.S. ${ }^{8}$ Furthermore, it should be noted that the division of the Latino sample by geographical region made for the purposes of this study could be further improved by analyzing each country on its own, or creating groups encompassing a smaller number of countries. This was not possible in our sample due to small numbers of Latinos born in certain countries, which required grouping by geographic area, and the assumption that geographically closer countries will have cultural commonalities.

Nevertheless, our approach was an improvement over previous studies that either did not assess Latinos separately or classified them all as one homogenous group.

\section{Conclusions and Future Directions}

This study sought to add to the scarce literature about Latinos who commit sexual offenses. The general findings of this study support previous suggestions in the literature of the need for more multicultural research, thus aiding in the development of culturally specific theories regarding the etiology and nature of sex offending. Needless to say, multicultural research is also necessary in treatment programming. One of the state-of-the-art ways that we manage those who commit sexual offenses is through the RNR approach, which stipulates that management should match the offender’s cultural background (Andrews \& Bonta, 1998;

Schaffer, Jeglic, Moster, \& Wnuk, 2010).

Understanding culturally relevant issues related to responsivity can help to inform service providers and treatment developers about salient adjustments or treatment modification in the development and implementation of culturally sensitive treatment programs. For example, given

\footnotetext{
${ }^{8}$ Although Mexicans are the largest Latino origin group in seven out of the ten largest states by Latino population, New Jersey is one of the three exceptions, with Puerto Ricans representing the largest Latino group in this state (Brown \& Lopez, 2013).
} 
that a part of the population was not born in the U.S., factors related to immigration and adaptation may need to be addressed. In addition, different patterns of sexual offending and the different characteristics of offenders are a clear responsivity factor and they warrant adjusted intervention approaches. Specifically for this population, it seems that treatment providers will need to bear in mind that the majority of Latinos in this sample were convicted of molestation of a minor child and often within the family. Consequently, this will likely result in loss of support upon release as the offenders will in all likelihood not be able to live with the family. Further, even if it was legally feasible to live with family following release, the nature of the crime may cause a loss of familial relationships_-thus building a post-release network of support for the offender may be necessary.

The findings of this study also suggest that there is a need within Latino populations to mitigate low rates of disclosure of sexual abuse, since victims of Latinos who commit sexual offenses are more likely to belong to their family and as such are frequently living with the offender. Not surprisingly, disclosing an offense that has occurred within the family means increased difficulties for the victim which consequently is associated with lower disclosure rates in comparison to cases of victimization by strangers (Hanson, Resnick, Saunders, Kilpatrick, \& Best, 1999; Smith et al., 2000). Therefore, prevention initiatives need to examine ways to overcome these difficulties. Suggested ways may be the inclusion of information regarding sexual abuse within the family in school and community prevention programs, as well as the possibility of offering financial support for families in which the offender is an important resource provider. Taking into account that disclosures are often delayed and made to persons outside the family in cases of familial sexual abuse, and following models suggested for Intimate Partner Violence, prevention efforts could focus on educating health care providers to implement 
more sensitive screening (Distel, 1999, Waalen, Goodwin, Spitz, Petersen, \& Saltzman, 2000). Future research should explore the specific barriers or concerns experienced by Latino victims with offenders within the family in order to understand different ethnic/cultural factors that may also have an influence in the decision to disclose. There is also a need to continue studying culturally specific risk and protective factors, as well as evaluating actuarial risk measures and their application to people from different ethnic backgrounds and country origin. Finally, taking into account that Latinos who commit sexual offenses may be exposed to different barriers in the community than their counterparts of other race/ethnicity, it would be useful to explore their specific needs in the process of reintegration.

In conclusion, there is no doubt that, along with the growing importance of Latino population in the U.S., we will also see an increased number of Latinos who commit sexual offenses in contact with the criminal justice system. More studies should be conducted on other racial and ethnic minority populations in order to gain a better understanding of the diversity of sex offending beyond those in the majority groups. Future research should pay particular attention to Latino populations and seek to provide a more nuanced examination of this population, taking into account country of origin, immigration status, and language fluency to better understand the influence of ethnicities on sex offending. 


\section{References}

Alegria, M., Canino, G., Shrout, P. E., Woo, M., Duan, N., Vila, D., ... Meng, X. L. (2008).

Prevalence of mental illness in immigrant and non-immigrant U.S. Latino groups. American Journal of Psychiatry, 165, 359-369. doi:10.1176/appi.ajp.2007.07040704

American Psychiatric Association. (2013). Diagnostic and statistical manual of mental disorders (5th ed.). Arlington, VA: American Psychiatric Publishing.

Andrews, D. A., \& Bonta, J. (1998). The psychology of criminal conduct (2nd ed.). Cincinnati, $\mathrm{OH}$ : Anderson.

Bales, W. D., \& Piquero, A. R. (2012). Racial/ethnic differentials in sentencing to incarceration. Justice Quarterly, 29, 742-773. doi:10.1080/07418825.2012.659674

Barbaree, H. E., Seto, M. C., Langton, C. M., \& Peacock, E. J. (2001). Evaluating the predictive accuracy of six risk assessment instruments for adult sex offenders. Criminal Justice and Behavior, 28, 490-521. doi:10.1177/009385480102800406

Bentall, R. (2003). Madness explained: Psychosis and human nature. London, New York: Penguin.

Brown, A., \& Lopez, M. H. (2013). Mapping the Latino population, by state, county and city. Washington, DC: Pew Research Center. Retrieved from http://www.pewhispanic.org/files/2013/08/latino_populations_in_the_states_ counties_and_cities_FINAL.pdf 
Burchard, E. G., Borrell, L. N., Choudhry, S., Naqvi, M., Tsai, H. J., Rodriguez-Santana, J. R., ... Arena, J. F. (2005). Latino populations: A unique opportunity for the study of race, genetics, and social environment in epidemiological research. American Journal of Public Health, 95, 2161-2168. doi:10.2105/AJPH.2005.068668

Burchfield, K. B., \& Mingus, W. (2008). Not in my neighborhood: Assessing registered sex offenders' experiences with local social capital and social control. Criminal Justice and Behavior, 35, 356-374. doi:10.1177/0093854807311375

Caravelis, C., Chiricos, T., \& Bales, W. (2011). Static and dynamic indicators of minority threat in sentencing outcomes: A multi-level analysis. Journal of Quantitative Criminology, 27, 405-425. doi:10.1007/s10940-011-9130-1

Carrasco, N., \& Garza-Louis, D. (1997). Hispanic sex offenders: cultural characteristics and implications for treatment. In B. K. Schwartz and H. R. Cellini (Eds.), Sex Offender: New Insights, Treatment Innovations and Legal Developments, (pp. 13-1 - 13-10). Kingston, N.J.: Civic Research Institute.

Cicchetti, D. V. (1994). Guidelines, criteria, and rules of thumb for evaluating normed and standardized assessment instruments in psychology. Psychological Assessment, 6, 284. doi:10.1037/1040-3590.6.4.284

Connor, P., \& Massey, D. (2011). Labor market insertion among Latino migrants to Spain and the United States: Differences by source country and legal status. Revista Internacional de Sociología, 69, 189-217. Retrieved from: http://www.ncbi.nlm.nih.gov/pmc/articles/PMC3923609/ 
Cullen, K., \& Travin, S. (1990). Assessment and treatment of Spanish-speaking sex offenders: special considerations. Psychiatric Quarterly, 61, 223-236. doi:10.1007/BF01064863

Distel, N. E. (1999). Disclosure of childhood sexual abuse: Links to emotion expression and adult attachment. Dissertation Abstracts: Section B: The Sciences and Engineering, 60(6B), 2938.

Flores de Apodaca, R. F., Schultz, J. M., Anderson, A. N., \& McLennan, M. D. (2005). Young, unassimilated Hispanic offenders: Absolutist vs. relativist cultural assumptions. Sexuality and Culture, 9, 3-23. doi:10.1007/s12119-005-1012-y

Gannon, T.A., \& Polaschek, D.L.L. (2006). Cognitive distortions in child molesters: A reexamination of key theories and research. Clinical Psychology Review, 26, 1000-1019. doi:10.1016/j.cpr.2005.11.010

Hanson, R. K., \& Harris, A. J. (1998). Dynamic predictors of sexual recidivism. User Report 1998-01. Ottawa, Ontario, Canada: Department of the Solicitor General of Canada.

Hanson, R. K., \& Harris, A. J. (2001). A structured approach to evaluating change among sexual offenders. Sexual Abuse: A Journal of Research and Treatment, 13, 105-122. doi:10.1177/107906320101300204

Hanson, R.K., Lunetta, A., Phenix, A., Neeley, M. B., \& Epperson, D. (2014). The field validity of static - 99/R sex offender risk assessment tool in California. Journal of Threat Assessment and Management. 1, 102-117. doi:10.1037/tam0000014 
Hanson, R. F., Resnick, H. S., Saunders, B. E., Kilpatrick, D. G., \& Best, C. (1999). Factors related to the reporting of childhood rape. Child Abuse \& Neglect, 23, 559-569. doi:10.1016/S0145-2134(99)00028-9

Hanson, R. K., Sheahan, C. L., \& VanZuylen, H. (2013). Static-99 and RRASOR predict recidivism among developmentally delayed sexual offenders: A cumulative metaanalysis. Sexual Offender Treatment, 8(1), 1-14. Retrieved from: http://www.sexualoffender-treatment.org/119.html

Hanson, R. K., \& Thornton, D. (2000). Improving risk assessments for sex offenders: A comparison of three actuarial scales. Law and Human Behavior, 24, 119-136. doi:10.1023/A:1005482921333

Heilbrun A. B., \& Cross, J. M. (1979). An analysis of rape patterns in White and Black rapists. The Journal of Social Psychology, 108, 83-87. doi:10.1080/00224545.1979 .9711964

Huston, R. L., Parra, J. M., Prihoda, T. J., \& Foulds, D. M. (1995). Characteristics of childhood sexual abuse in a predominantly Mexican-American population. Child Abuse \& Neglect, 19, 165-176. doi:10.1016/0145-2134(94)00114-A

Kenny, M. C., \& McEachern, A. G. (2000). Racial, ethnic, and cultural factors of childhood sexual abuse: A selected review of the literature. Clinical Psychology Review, 20, 905922. doi:10.1016/S0272-7358(99)00022-7

Kilgust, A. R. (2009). Sentencing and risk characteristics of Latino sexual offenders (Master's Thesis, Pacific University). Retrieved from: http://commons.pacificu.edu/spp/96 
Kirk, S. A. (1975). The sex offenses of Blacks and Whites. Archives of Sexual Behavior, 4, 295302. doi:10.1007/BF01541629

Kouyoumdjian, H., Zamboanga, B.L., \& Hansen, D.J. (2003). Barriers to community mental health services for Latinos: Treatment considerations. Clinical Psychology: Science and Practice, 10, 394-422. doi:10.1093/clipsy.bpg041

Långström, N. (2004). Accuracy of actuarial procedures for assessment of sexual offender recidivism risk may vary across ethnicity. Sexual Abuse: A Journal of Research and Treatment, 16, 107-120. doi:10.1177/107906320401600202

Larcombe, W. (2012). Sex offender risk assessment: The need to place recidivism research in the context of attrition in the criminal justice system. Violence Against Women, 18, 482-501. doi:10.1177/1077801212452249

Leguizamo, A., Lee, S. C., Jeglic, E. L., \& Calkins, C. (2015). Utility of the Static-99 and Static99R with Latino sex offenders. Sexual Abuse: A Journal of Research and Treatment. Advance online publication. doi:10.1177/1079063215618377

Leguizamo, A., Peltzman, B., Carrasco, N., Nosal, M., \& Woods, L. (2010, April). Ethnic differences among incarcerated sex offenders. Paper presented at the 12th Annual Joint Conference of the Massachusetts Adolescent Sexual Offender Coalition and the Massachusetts Association for the Treatment of Sexual Abusers. Marlborough, MA.

Levenson, J. S., Brannon, Y. N., Fortney, T., \& Baker, J. (2007). Public perceptions about sex offenders and community protection policies. Analyses of Social Issues and Public Policy, 7, 137-161. doi:10.1111/j.1530-2415.2007.00119.x 
London, K., Bruck, M., Ceci, S. J., \& Shuman, D. W. (2005). Disclosure of child sexual abuse: What does the research tell us about the ways that children tell? Psychology, Public Policy, and Law, 11, 194-216. doi:10.1037/1076-8971.11.1.194

Lopez, M., \& Livingston, G. (2009). Hispanics and the criminal justice system: Low confidence, high exposure. Washington, DC: Pew Research Center. Retrieved from http://www.pewhispanic.org/2009/04/07/hispanics-and-the-criminal-justice-system/

Mercado, C. C., Jeglic, E., \& Markus, K (2011). Sex offender management, treatment, and civil commitment: An evidence based analysis aimed at reducing sexual violence. US Department of Justice, 1, 2-81. Retrieved from http://www.ncdsv.org/images/SOmanagement-treatment-and-civil-commitment_9-2013.pdf

Moro, P. E. (1998). Treatment for Hispanic sexual offenders. In W. L. Marshall, Y. M. Fernandez, S. M. Hudson, \& T. Ward (Eds.), Sourcebook of treatment programs for sexual offenders (pp. 445-456). New York, US: Springer US.

Murphy, W. D., DiLillo, D., Haynes, M. R., \& Steere, E. (2001). An exploration of factors related to deviant sexual arousal among juvenile sex offenders. Sexual Abuse: A Journal of Research and Treatment, 13, 91-103. doi:10.1177/107906320101300203

Patel, K., \& Lord, A. (2001). Ethnic minority sex offenders' experiences of treatment. Journal of Sexual Aggression, 7, 40-50. doi:10.1080/13552600108413320

Priebe, G, \& Svedin, C. G. (2008). Child sexual abuse is largely hidden from the adult society: An epidemiological study of adolescents’ disclosures. Child Abuse \& Neglect, 32, 10951108. doi:10.1016/j.chiabu.2008.04.001 
Quesada, S. P., Calkins, C., \& Jeglic, E. L. (2014). An examination of the interrater reliability between practitioners and researchers on the Static-99. International Journal of Offender Therapy and Comparative Criminology, 58, 1364-1375. doi:10.1177/0306624X13495504

Ramakers, A. A., Van Wilsem, J. A., Nieuwbeerta, P., \& Dirkzwager, A. J. (2016). Returning to a former employer: A potentially successful pathway to ex-prisoner reemployment. British Journal of Criminology, 56, 668-688. doi:10.1093/bjc/azv063

Santana, M. C., Raj, A., Decker, M. R., La Marche, A., \& Silverman, J. G. (2006). Masculine gender roles associated with increased sexual risk and intimate partner violence perpetration among young adult men. Journal of Urban Health, 83, 575-585. doi:10.1007/s11524-006-9061-6

Schaffer, M., Jeglic, E. L., Moster, A., \& Wnuk, D. (2010). Cognitive-behavioral therapy in the treatment and management of sex offenders. Journal of Cognitive Psychotherapy, 24, 92103. doi:10.1891/0889-8391.24.2.92

Seto, M. C. \& Lalumiere, M. L. (2010). What is so special about male adolescent sexual offending? A review and test of explanations through meta-analysis. Psychological Bulletin, 136, 526. doi:10.1037/a0019700

Smith, D., Letourneau, E. J., Saunders, B. E., Kilpatrick, D. G., Resnick, H. S., \& Best, C. L. (2000). Delay in disclosure of childhood rape: Results from a national survey. Child Abuse \& Neglect, 24, 273-287. doi:10.1016/S0145-2134(99)00130-1

Smith-Socaris, C., Perry, R. A., \& Fox-Mullen, L. (2006). Racial and ethnic demographics of the New York state level 3 sex offender population. New York Civil Liberties Union. 
Retrieved from

https://www.nyclu.org/sites/default/files/sexoffender_analysis_121106.pdf

Spohn, C. \& Holleran, D. (2000). The imprisonment penalty paid by young, unemployed Black and Hispanic male offenders. Criminology, 38, 281-306. doi:10.1111/j.17459125.2000.tb00891.x

Steffensmeier, D., \& Demuth, S. (2000). Ethnicity and sentencing outcomes in US federal courts: Who is punished more harshly? American Sociological Review, 65 (5) 705-729. Retrieved from http://www.icpsr.umich.edu/summerprog/2009/nijworkshop/SteffDemuth2000FederalStudy.pdf

Steffensmeier, D., \& Demuth, S. (2001). Ethnicity and judges' sentencing decisions: HispanicBlack- White comparisons. Criminology, 39, 145-178. doi:10.1111/j.17459125.2001.tb00919.x

Stepler, R., \& Brown, A. (2016). Statistical portrait of Hispanics in the United States. Washington, DC: Pew Research Center. Retrieved from www.pewhispanic.org/2016/04/19/statistical-portrait-of-hispanics-in-the-united-states-key-charts/

Stowell, J. I., Martinez, R., \& Cancino, J. M. (2012). Latino crime and Latinos in the criminal justice system: Trends, policy implications, and future research initiatives. Race and Social Problems, 4, 31-40. doi:10.1007/s12552-012-9067-5

Ulmer, J. T., \& Johnson, B. (2004). Sentencing in context: A multilevel analysis. Criminology, 42, 137-178. doi:10.1111/j.1745-9125.2004.tb00516.x 
Varela, J. G., Boccaccini, M. T., Murrie, D. C., Caperton, J. D., \& Gonzalez E. (2013). Do the Static-99 and Static-99R perform similarly for White, Black, and Latino sexual offenders? International Journal of Forensic Mental Health, 12, 231-243. doi:10.1080/14999013.2013.846950

Varghese, F. P., Hardin, E. E., \& Bauer, R. L. (2009). Factors influencing the employability of Latinos: the roles of ethnicity, criminal history, and qualifications. Race and Social Problems, 1, 171-181. doi:10.1007/s12552-009-9014-2

Visher, C. A., Debus, S., \& Yahner, J. (2008). Employment after prison: a longitudinal study of releases in three states. Justice Policy Center Research Brief. Washington, DC: Urban Institute.

de Vries Robbe, M., Mann, R. E., Maruna, S., \& Thornton, D. (2015). An exploration of protective factors supporting desistance from sexual offending. Sexual Abuse: A Journal of Research and Treatment, 27, 16-33. doi:10.1177/1079063214547582

Waalen, J., Goodwin, M. M., Spitz, A. M., Petersen, R., \& Saltzman, L. E. (2000). Screening for intimate partner violence by health care providers: Barriers and interventions. American Journal of Preventive Medicine, 19(4), 230-237. Retrieved from http://www.ncbi.nlm.nih.gov/pubmed/11064226

Ward, T., \& Beech, A. (2006). An integrated theory of sexual offending. Aggression and Violent Behavior, 11, 44-63. doi:10.1016/j.avb.2005.05.002 
Table 1

Characteristics of the White, African American, and Latino samples in terms of age (means) and countries of origin

\begin{tabular}{|c|c|c|c|c|c|}
\hline & \multirow[b]{2}{*}{$\begin{array}{l}\text { Age } \\
(M, S D)\end{array}$} & \multicolumn{4}{|c|}{ Country of origin } \\
\hline & & $\frac{\text { U.S. }}{n(\%)}$ & $\frac{\text { Latin American }}{n(\%)}$ & $\frac{\text { Other }}{n(\%)}$ & $\frac{\text { Unknown }}{n(\%)}$ \\
\hline White & $(47.9,13.4)$ & 1237 (94.4\%) & $9(0.68 \%)$ & $51(3.89 \%)$ & $13(0.9 \%)$ \\
\hline African-American & $(42.4,10.4)$ & 1085 (93.7\%) & $7(0.6 \%)$ & 50 (5.18\%) & $6(0.52 \%)$ \\
\hline Latino $^{\mathrm{a}}$ & $(43.2,11.5)$ & & & & \\
\hline
\end{tabular}

${ }^{\mathrm{a}}$ Country of origin for the Latino participants is reported in text

Table 2

Chi-square comparison of Whites, African-Americans, and Latinos convicted of sexual offenses on demographic variables

\begin{tabular}{|c|c|c|c|c|c|c|}
\hline & $\frac{\text { White }}{n(\%)}$ & $\frac{\text { African-American }}{n(\%)}$ & $\frac{\text { Latino }}{n(\%)}$ & $X^{2}$ & $d f$ & $V$ \\
\hline Reported childhood abuse/neglect & $503(40.8)$ & $321(30.7)$ & $185(31.2)$ & $30.575^{* * *}$ & 2 & 0.103 \\
\hline Psychiatric history & $532(41.8)$ & $318(28.5)$ & $154(25.0)$ & $71.894^{* * *}$ & 2 & 0.155 \\
\hline Low educational level & $115(8.9)$ & $80(7.0)$ & $152(24.4)$ & $172.319^{* * *}$ & 4 & 0.168 \\
\hline Low SES level & $331(63.3)$ & $376(82.5)$ & $209(76.6)$ & $57.254^{* * *}$ & 4 & 0.151 \\
\hline Prior employment & $981(77.2)$ & $733(65.9)$ & $501(81.3)$ & $62.254^{* * *}$ & 2 & 0.144 \\
\hline
\end{tabular}

$* p<0.05 * * p<0.01 * * * p<0.001$

Table 3

Chi-square comparisons of Whites, African-Americans, and Latinos convicted of sexual offenses on index offense variables 


\begin{tabular}{|c|c|c|c|c|c|c|c|}
\hline & & $n(\%)$ & $n(\%)$ & $n(\%)$ & $X^{2}$ & $d f$ & V \\
\hline Type of index & Adult sexual assault & $162(12.5)$ & $299(26.1)$ & $88(14.0)$ & $145.390^{* * *}$ & 14 & 0.154 \\
\hline \multirow{3}{*}{ offense } & Molestation of a minor child & 979 (75.3) & $746(65.2)$ & 497 (79.3) & & & \\
\hline & Voyeurism or exhibitionism & $34(2.6)$ & $10(0.9)$ & $9(0.3)$ & & & \\
\hline & Computer sex-related crime & $23(1.8)$ & $1(0.1)$ & $1(0.2)$ & & & \\
\hline Offense & Physical contact involved & $1219(93.7)$ & $1120(98.0)$ & $614(97.6)$ & $34.721^{* * *}$ & 2 & 0.106 \\
\hline \multirow[t]{7}{*}{ behaviors } & Pornography involved & $127(13.0)$ & $28(1.1)$ & $27(5.3)$ & $77.480^{* * *}$ & 2 & 0.177 \\
\hline & Alcohol or drugs involved & $420(35.2)$ & $358(37.1)$ & $183(32.0)$ & 4.068 & 2 & 0.039 \\
\hline & $\begin{array}{l}\text { Alcohol or drugs supplied to } \\
\text { the victim }\end{array}$ & $90(20.0)$ & $60(13.8)$ & $26(10.8)$ & $11.808^{* *}$ & 2 & 0.102 \\
\hline & Offender intoxicated & 245 (57.4) & $231(21.8)$ & 111 (48.9) & 5.075 & 2 & 0.69 \\
\hline & Offender physically violent & 107 (13.7) & $223(26.5)$ & $58(13.8)$ & $53.903^{* * *}$ & 4 & 0.115 \\
\hline & Use of a weapon & $67(5.2)$ & 165 (14.7) & $47(7.5)$ & $66.893^{* * *}$ & 2 & 0.149 \\
\hline & Use of threats & 136 (17.3) & $208(24.6)$ & $82(19.6)$ & $13.426^{* *}$ & 2 & 0.081 \\
\hline
\end{tabular}

$* p<0.05 * * p<0.01 * * * p<0.001$

Table 4

Chi-square comparisons of Whites, African-Americans, and Latinos convicted of sexual offenses on victim variables

\begin{tabular}{|c|c|c|c|c|c|c|c|}
\hline & & $\frac{\text { White }}{n(\%)}$ & $\frac{\text { African-American }}{n(\%)}$ & $\frac{\text { Latino }}{n(\%)}$ & $X^{2}$ & $d f$ & $V$ \\
\hline Victim & Male victim & $252(19.8)$ & $101(8.9)$ & $47(7.6)$ & $124.726^{* * *}$ & 4 & 0.144 \\
\hline \multirow[t]{5}{*}{ characteristics } & Female victim & $953(75.0)$ & $1018(89.8)$ & $561(90.3)$ & & & \\
\hline & Male and female & $65(5.1)$ & $14(1.2)$ & $13(2.1)$ & & & \\
\hline & Younger than 13 & 697 (57.3) & $452(45.3)$ & $361(61.4)$ & $67.584^{* * *}$ & 4 & 0.110 \\
\hline & $13-17$ & 406 (33.4) & $374(37.5)$ & $183(31.1)$ & & & \\
\hline & Older than 13 & $113(9.3)$ & $171(17.2)$ & $44(7.5)$ & & & \\
\hline \multirow[t]{2}{*}{$\begin{array}{l}\text { Relationship with the } \\
\text { victim }\end{array}$} & $\begin{array}{l}\text { Offender living with } \\
\text { the victim }\end{array}$ & $227(29.8)$ & $206(25.1)$ & 165 (40.3) & $30.394^{* * *}$ & 2 & 0.123 \\
\hline & Immediate family & $150(11.8)$ & $74(6.6)$ & $52(8.3)$ & $71.715^{* * *}$ & 16 & 0.109 \\
\hline
\end{tabular}




\begin{tabular}{clll} 
Extended family & $155(12.1)$ & $136(12.1)$ & $94(15.1)$ \\
Stepfamily & $171(13.4)$ & $100(8.9)$ & $93(14.9)$ \\
Acquaintance & $516(40.4)$ & $538(47.9)$ & $267(42.8)$ \\
Stranger & $178(13.9)$ & $190(16.9)$ & $62(9.9)$ \\
\hline$* p<0.05 * * p<0.01 * * * p<0.001$ & &
\end{tabular}

Table 5

Chi-square comparisons of Whites, African-Americans, and Latinos convicted of sexual offenses on criminal history variables

\begin{tabular}{|c|c|c|c|c|c|c|}
\hline & $\frac{\text { White }}{n(\%)}$ & $\frac{\text { African-American }}{n(\%)}$ & $\frac{\text { Latino }}{n(\%)}$ & $X^{2}$ & $d f$ & V \\
\hline Charged/convicted of a sexual crime & $381(30.7)$ & $370(33.8)$ & $113(18.8)$ & $43.787^{* * *}$ & 2 & 0.122 \\
\hline Charged/convicted of a non-sexual crime & $789(61.4)$ & $957(83.8)$ & $365(58.2)$ & $185.528^{* * *}$ & 2 & 0.247 \\
\hline Charged/convicted as a juvenile & $264(24.8)$ & $386(38.8)$ & $77(15.6)$ & $99.554^{* * *}$ & 2 & 0.197 \\
\hline $\begin{array}{l}\text { Charged/`convicted for a sexual crime as a } \\
\text { juvenile }\end{array}$ & $85(13.4)$ & $113(16.5)$ & $17(6.1)$ & $18.515^{* * *}$ & 2 & 0.108 \\
\hline
\end{tabular}

${ }^{*} p<0.05 * * p<0.01 * * * p<0.001$

Table 6

Chi-square comparison of Latinos convicted of sexual offenses grouped by countries of origin on demographic variables

\begin{tabular}{|c|c|c|c|c|c|c|c|}
\hline & $\frac{\mathrm{U} . \mathrm{S} .}{n(\%)}$ & $\frac{\text { Puerto Rico }}{n(\%)}$ & $\frac{\text { Central America }}{n(\%)}$ & $\frac{\text { South America }}{n(\%)}$ & $X^{2}$ & $d f$ & $V$ \\
\hline $\begin{array}{l}\text { Reported childhood abuse/ } \\
\text { neglect }\end{array}$ & $82(41.2)$ & $52(38.5)$ & $36(20.8)$ & $12(16.2)$ & $29.024^{* * *}$ & 3 & 0.224 \\
\hline Psychiatric history & 71 (33.3) & 48 (34.8) & 25 (14.1) & 7 (9.1) & $36.532^{* * *}$ & 3 & 0.246 \\
\hline Low educational level & $29(13.4)$ & $40(28.2)$ & $65(35.7)$ & $16(20.0)$ & $38.325^{* * *}$ & 6 & 0.176 \\
\hline Middle SES level & $13(6.2)$ & $5(3.6)$ & $10(5.6)$ & $13(16.7)$ & $20.273^{*}$ & 9 & 0.106 \\
\hline Low SES level & $63(33)$ & $52(37.1)$ & $60(33.7)$ & $30(38.5)$ & & & \\
\hline High SES level & $6(2.9)$ & $4(2.9)$ & $7(3.9)$ & $3(3.8)$ & & & \\
\hline
\end{tabular}


Prior employment $169(80.5)$

$92(65.7)$

$154(88.0)$

$75(93.8)$

$35.303^{* *}$

3

0.242

${ }^{*} p<0.05 * * p<0.01 * * * p<0.001$

Table 7

Chi-square comparison of Latinos convicted of sexual offenses grouped by countries of origin on index offense variables

\begin{tabular}{|c|c|c|c|c|c|c|c|c|}
\hline & & $\begin{array}{l}\text { U.S. } \\
n(\%)\end{array}$ & $\frac{\frac{\text { Puerto }}{\text { Rico }}}{n(\%)}$ & Central America & $\frac{\text { South }}{\text { America }}$ & $X^{2}$ & $d f$ & $V$ \\
\hline \multirow{4}{*}{$\begin{array}{l}\text { Type of } \\
\text { index } \\
\text { offense }^{\text {a }}\end{array}$} & Adult sexual assault & $27(12.5)$ & $20(14.3)$ & $32(17.9)$ & $6(10.0)$ & & & \\
\hline & Molestation of a minor child & $175(81.0)$ & $110(78.6)$ & $137(76.5)$ & $65(81.3)$ & & & \\
\hline & Voyeurism or exhibitionism & $1(0.5)$ & $1(0.7)$ & $3(1.7)$ & $4(5.0)$ & & & \\
\hline & Computer sex-related crime & $1(0.5)$ & $0(0)$ & $0(0)$ & $0(0)$ & & & \\
\hline \multirow{8}{*}{$\begin{array}{l}\text { Offense } \\
\text { behaviors }\end{array}$} & Physical contact involved & $210(97.7)$ & $137(97.9)$ & $179(98.4)$ & $76(95.0)$ & 2.755 & 3 & 0.067 \\
\hline & Pornography involved & $9(5.5)$ & $9(7.6)$ & $6(3.8)$ & $3(4.9)$ & 1.923 & 3 & 0.589 \\
\hline & Alcohol or drugs involved & 68 (34.9) & 49 (38.3) & 48 (29.3) & $15(20.5)$ & 7.998 & 3 & 0.120 \\
\hline & $\begin{array}{l}\text { Alcohol or drugs supplied to the } \\
\text { victim }\end{array}$ & $8(10.7)$ & $5(8.8)$ & $10(12.0)$ & $3(13.0)$ & 0.490 & 3 & 0.921 \\
\hline & Offender intoxicated & 36 (56.3) & $31(56.4)$ & $35(42.2)$ & $7(31.8)$ & 6.680 & 3 & 0.173 \\
\hline & Offender physically violent ${ }^{\mathrm{a}}$ & $14(10.6)$ & $11(11.6)$ & $27(18.6)$ & $5(10.0)$ & & & \\
\hline & Use of a weapon & $16(7.4)$ & $12(8.7)$ & $14(7.8)$ & $5(6.3)$ & 0.452 & 3 & 0.027 \\
\hline & Use of threats & $32(24.4)$ & $15(16.1)$ & $30(21.0)$ & $4(8.3)$ & 6.707 & 3 & 0.082 \\
\hline
\end{tabular}

${ }^{a}$ No statistical result is reported due to the violation of assumptions

Table 8

Chi-square comparison of Latinos convicted of sexual offenses grouped by countries of origin on victim variables

$\begin{array}{llllll}\text { U.S. } & \text { Puerto Rico } & \frac{\text { Central America }}{n(\%)} & \frac{\text { South America }}{n(\%)} & X^{2} & d f\end{array}$




\begin{tabular}{|c|c|c|c|c|c|c|c|c|}
\hline Victim & Male victim ${ }^{\mathrm{a}}$ & 20 (9.3) & $10(7.4)$ & $9(5.1)$ & $8(10.0)$ & \multirow{12}{*}{9.392} & \multirow{12}{*}{6} & \multirow{12}{*}{.090} \\
\hline \multirow{5}{*}{ characteristics } & Female victim $^{\mathrm{a}}$ & $189(87.9)$ & $122(89.7)$ & 167 (93.8) & $71(88.0)$ & & & \\
\hline & Male and female ${ }^{\mathrm{a}}$ & $6(2.8)$ & $4(2.9)$ & $2(1.1)$ & $1(1.3)$ & & & \\
\hline & Minor than 13 & $116(58.3)$ & $88(66.7)$ & $96(56.8)$ & $52(67.5)$ & & & \\
\hline & $13-17$ & $66(33.2)$ & $31(23.5)$ & $63(37.3)$ & $21(27.3)$ & & & \\
\hline & Older than 13 & $17(8.5)$ & $13(9.8)$ & $10(5.9)$ & $4(5.2)$ & & & \\
\hline $\begin{array}{l}\text { Relationship } \\
\text { with the }\end{array}$ & $\begin{array}{l}\text { Offender living with } \\
\text { the victim }\end{array}$ & $44(33.6)$ & $42(44.7)$ & $56(38.4)$ & $22(44.0)$ & & & \\
\hline \multirow[t]{5}{*}{ victim $^{a}$} & Immediate family & 17 (7.9) & $9(6.5)$ & 19 (10.7) & $5(6.3)$ & & & \\
\hline & Extended family & $30(14.0)$ & $21(15.1)$ & $28(15.7)$ & $15(18.8)$ & & & \\
\hline & Stepfamily & $29(13.5)$ & $21(15.1)$ & $26(14.6)$ & $15(18.8)$ & & & \\
\hline & Acquaintance & 93 (43.3) & $59(42.4)$ & 81 (45.5) & $28(35.0)$ & & & \\
\hline & Stranger & $25(11.6)$ & $13(9.4)$ & $14(7.9)$ & $10(12.5)$ & & & \\
\hline
\end{tabular}

a: No statistical result is reported due to the violation of assumptions

Table 9

Chi-square comparison of Latinos convicted of sexual offenses grouped by countries of origin on criminal history variables

\begin{tabular}{|c|c|c|c|c|c|c|c|}
\hline & $\frac{\text { U.S. }}{n(\%)}$ & $\frac{\text { Puerto Rico }}{n(\%)}$ & $\frac{\text { Central America }}{n(\%)}$ & $\frac{\text { South America }}{n(\%)}$ & $X^{2}$ & $d f$ & $V$ \\
\hline Charged/convicted of a sexual crime & $60(29.3)$ & $31(22.5)$ & $10(5.8)$ & $11(14.5)$ & $35.892^{* * *}$ & 3 & 0.246 \\
\hline $\begin{array}{l}\text { Charged/convicted of a non-sexual } \\
\text { crime }^{\text {a }}\end{array}$ & $157(73.0)$ & $88(62.4)$ & $87(48.1)$ & $31(39.2)$ & & & \\
\hline Charged/convicted as a juvenile & $55(30.1)$ & $15(14.3)$ & $5(3.6)$ & $2(3.2)$ & $50.674^{* * *}$ & 3 & 0.323 \\
\hline $\begin{array}{l}\text { Charged/convicted for a sexual } \\
\text { crime as a juvenile }^{\text {a }}\end{array}$ & $14(13.1)$ & $2(3.4)$ & $1(1.3)$ & $0(0)$ & & & \\
\hline
\end{tabular}
crime as a juvenile ${ }^{\mathrm{a}}$

a: No statistical result is reported due to the violation of assumptions

${ }^{*} p<0.05 * * p<0.01 * * * p<0.001$ 